\title{
Median Arcuate Ligament Syndrome Clinical Presentation, Pathophysiology, and Management: Description of Four Cases
}

\author{
Ihsan Al Bayati ${ }^{1}$, Mahesh Gajendran ${ }^{2, *}$, Brian R. Davis ${ }^{3}{ }^{-}$, Jesus R. Diaz ${ }^{4}$ and Richard W. McCallum ${ }^{1,5}$ \\ 1 Division of Gastroenterology, Paul L Foster School of Medicine, Texas Tech University Health Sciences Center \\ El Paso, El Paso, TX 79905, USA; Ihsan.Al-Bayati@ttuhsc.edu (I.A.B.); Richard.Mccallum@ttuhsc.edu (R.W.M.) \\ 2 Department of Internal Medicine, Paul L Foster School of Medicine, Texas Tech University Health Sciences \\ Center El Paso, El Paso, TX 79905, USA \\ 3 Department of Surgery, Paul L Foster School of Medicine, Texas Tech University Health Sciences Center El \\ Paso, El Paso, TX 79905, USA; br.davis@ttuhsc.edu \\ 4 Department of Radiology, Paul L Foster School of Medicine, Texas Tech University Health Sciences Center El \\ Paso, El Paso, TX 79905, USA; jesus.diaz@ttuhsc.edu \\ 5 Center for Neurogastroenterology and GI Motility, Paul L Foster School of Medicine, Texas Tech University \\ Health Sciences Center El Paso, El Paso, TX 79905, USA \\ * Correspondence: Mahesh.gajendran@ttuhsc.edu; Tel.: +1-915-215-8400
}

check for updates

Citation: Bayati, I.A.; Gajendran, M.; Davis, B.R.; Diaz, J.R.; McCallum, R.W. Median Arcuate Ligament Syndrome Clinical Presentation, Pathophysiology, and Management: Description of Four Cases. Gastrointest. Disord. 2021, 3, 44-50. https://doi.org/10.3390/gidisord 3010005

Received: 23 December 2020 Accepted: 10 February 2021 Published: 26 February 2021

Publisher's Note: MDPI stays neutral with regard to jurisdictional claims in published maps and institutional affiliations.

Copyright: (c) 2021 by the authors. Licensee MDPI, Basel, Switzerland. This article is an open access article distributed under the terms and conditions of the Creative Commons Attribution (CC BY) license (https:/ / creativecommons.org/licenses/by/ $4.0 /)$.

\begin{abstract}
Median arcuate ligament syndrome (MALS), otherwise called celiac artery compression syndrome (CACS), is an uncommon disorder that results from an anatomical compression of the celiac axis and/or celiac ganglion by the MAL. Patients typically present with abdominal pain of unknown etiology exacerbated by eating along with nausea, vomiting, and weight loss. MALS is a diagnosis of exclusion that should be considered in patients with severe upper abdominal pain, which does not correlate with the objective findings. The cardinal feature which is elicited in the diagnosis of MALS relies on imaging studies of the celiac artery, demonstrating narrowing during expiration. The definitive treatment is the median arcuate ligament's surgical release to achieve surgical decompression of the celiac plexus by division of the MAL. This article describes our experience with this entity, focusing on symptom presentation, diagnostic challenges, and management, including long-term follow-up in four cases.
\end{abstract}

Keywords: case series; celiac artery; celiac plexus; median arcuate ligament; clinical presentation; pathophysiology; management

\section{Introduction}

Median arcuate ligament syndrome (MALS), otherwise called celiac artery compression syndrome (CACS), is an uncommon disorder first described in 1965 by Dunbar et al. [1]. The median arcuate ligament is a muscular arch that connects the diaphragmatic crura to form the anterior margin of the aortic hiatus. In patients with MALS, it causes compression of the celiac artery on expiration and entrapment of the celiac plexus (a dense network of ganglia that lies over the anterolateral aorta at the T12 vertebral level) [2]. The pathophysiology of MALS is related to both ischemic and neuropathic mechanisms due to the anatomic relationship of the MAL to the origin of the arterial celiac plexus and ganglion [3] (Figure 1). 


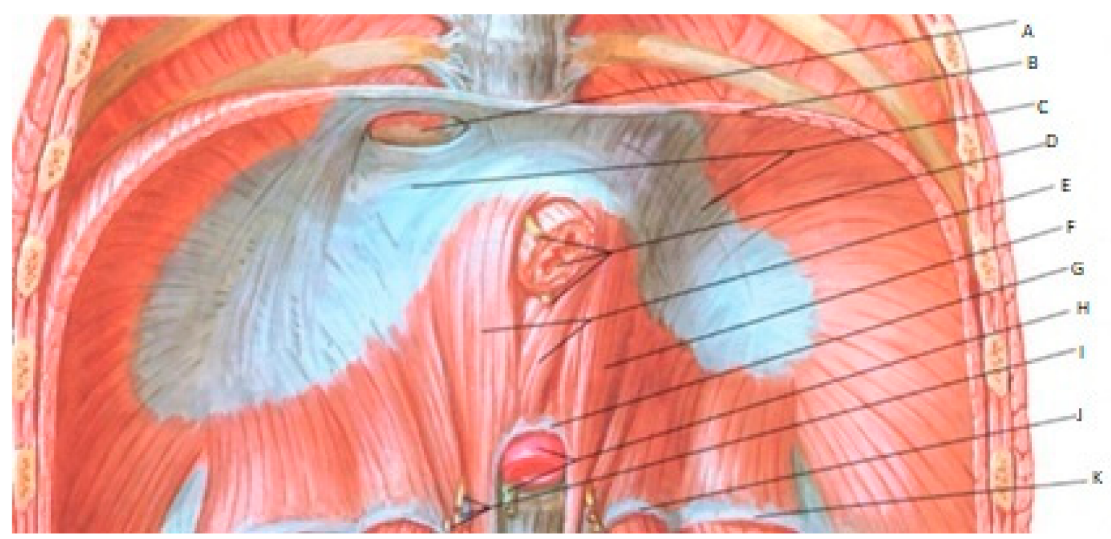

Figure 1. Anatomical relationship of the median arcuate ligament (MAL) to the diaphragm and the aorta. (A) Vena Caval Foramen; (B) Diaphragm; (C) Central Tendon of Diaphragm; (D) Esophagus and Vagus Nerves; (E) Right Crus of Diaphragm; (F) Left Crus of Diaphragm; (G) Median Arcuate Ligament; (H) Aorta and Thoracic Duct; (I) Thoracic Splanchnic Nerves and Azygos Vein; (J) Median Arcuate Ligament (medial lumbocostal arch); (K) Lateral Arcuate Ligament (lateral lumbocostal arch) (Reproduced from McCallum et al. [4] with permission from Practical Gastro).

Theories have been proposed to explain the altered anatomy of the median arcuate ligament, including a congenital anomaly [2]. A traumatic origin has also been hypothesized, causing a change of the diaphragm anatomy, resulting in an alteration of the diaphragm's aortic hiatus [5-7]. The manifestations of symptoms in adults could be explained by a combination of a congenitally early take-off origin of the celiac artery and/or an abnormally thickened MAL with or without arteriosclerosis that may predispose to the "arterial narrowing" on expiration.

The typical symptom in MALS is chronic epigastric pain aggravated by meals. Other symptoms include nausea, vomiting, and accompanying weight loss. In about $35 \%$ of the patients, an abdominal bruit can be auscultated [8]. MALS is a diagnosis of exclusion that should be considered in patients with severe upper abdominal pain that is out of proportion and does not correlate with the objective findings. The cardinal feature used in the diagnosis of MALS, which is demonstrated by imaging studies, is the compression of the celiac artery during expiration and reduction in this compression during inspiration, demonstrated on ultrasound or conventional angiographic imaging. The detection of an abnormal gastric electric rhythm in patients with MALS is suggestive of neurogenic pathogenesis [9]. The definitive treatment is the surgical release of the median arcuate ligament to achieve decompression of the celiac plexus. This article describes our experience with this entity, focusing on symptom presentation, diagnostic challenges, and management, including long-term follow-up.

\section{Results}

Four patients with MALS were identified from the experience of a gastroenterologist (RMC) at an academic referral center directing a center for GI motility and functional bowel disorders from January 2017-June 2020. The demographics of all patients included in the study are summarized in Table 1 . All four patients were females with a median age of 34.5 (IQR 28.5, 42.3) years. The initial presenting complaint in all four patients was chronic abdominal pain of unknown etiology despite an extensive evaluation from the previous providers. All four patients were found to have delayed gastric emptying that did not improve with the medical treatment they had received, and hence they were referred to our center. The median duration of symptoms before presentation was 3 (IQR 2,4.8) years. All the patients had increased peak systolic velocity (PSV) on the celiac artery on Doppler ultrasound during expiration and more than $50 \%$ narrowing of the celiac artery on the aortic aortogram during expiration. Most of the patients (75\%) underwent a celiac plexus block using xylocaine with a temporary improvement of symptoms. Eventually, they were 
referred to surgical evaluation, and all the patients underwent release of the median arcuate ligament (MAL). All patients recovered well from the surgery with the resolution of the abdominal pain during long-term follow-up along with documentation of improvement in the abdominal aortogram and duplex ultrasound (Table 2).

Table 1. Demographics, clinical symptoms, diagnostic studies, treatment, and outcomes of patients with Median Arcuate Ligament Syndrome (MALS).

\begin{tabular}{lc}
\hline \multicolumn{1}{c}{ Characteristics } & Patients \\
& $\boldsymbol{N}=\mathbf{4}(\mathbf{\%})$ \\
\hline Median Age (Interquartile Range [IQR]) in years & $34.5(28.5,42.25)$ \\
Female Gender & $4(100)$ \\
Symptoms & \\
- Abdominal Pain & $4(100)$ \\
- Nausea or Vomiting & $3(75)$ \\
- Weight Loss & $2(50)$ \\
Duration of symptoms in years & $3(2,4.75)$ \\
Delayed Gastric Emptying Study & $4(100)$ \\
Increased Doppler Ultrasound Peak Systolic Velocity & $4(100)$ \\
Abdominal aortogram during expiration & $4(100)$ \\
Celiac Block & $3(75)$ \\
Celiac Artery Stent & $1(25)$ \\
Surgical MAL release & $4(100)$ \\
Resolution of Abd Pain Post-op & $4(100)$ \\
\hline
\end{tabular}

Table 2. Clinical presentation of the patients.

\begin{tabular}{|c|c|c|c|c|}
\hline Patients & Patient 1 & Patient 2 & Patient 3 & Patient 4 \\
\hline Age in Years & 55 & 38 & 21 & 31 \\
\hline Gender & Female & Female & Female & Female \\
\hline History of previous abdominal surgery & Cholecystectomy & None & None & None \\
\hline Presenting Symptoms & $\mathrm{AP}, \mathrm{N}, \mathrm{V}$ & $\begin{array}{c}\mathrm{AP}, \mathrm{N}, \mathrm{V}, \\
\text { Wt Loss }(5 \% \text { over } \\
2 \text { years })\end{array}$ & $\mathrm{AP}$ & $\begin{array}{c}\mathrm{AP}, \mathrm{N}, \mathrm{V}, \\
\text { Wt loss }(8 \% \text { over } \\
2 \text { years })\end{array}$ \\
\hline Duration of Symptoms (years) & 7 & 2 & 4 & 2 \\
\hline GES at 4 hours & $19 \%$ & $15 \%$ & $31 \%$ & $10 \%$ \\
\hline DU PSV of Celiac Artery, cm/sec & 362 & 323 & 339 & 440 \\
\hline $\begin{array}{c}\text { Narrowing of Celiac Artery on } \\
\text { Abdominal Aortogram during expiration }\end{array}$ & $54 \%$ & $66 \%$ & $58 \%$ & $60 \%$ \\
\hline Underwent Celiac Block & Yes & Yes & No & Yes \\
\hline Underwent Celiac artery Stent & No & Yes & No & No \\
\hline Surgical Treatment & Yes & Yes & Yes & Yes \\
\hline Pyloroplasty and GES & No & No & Yes & No \\
\hline Post-op PSV of Celiac Artery, cm/sec & 130 & 178 & 207 & 151 \\
\hline Post-op Aortogram & normal & normal & normal & Not available \\
\hline Resolution of Abd Pain Post-op & Yes & Yes & Yes & Yes \\
\hline $\begin{array}{l}\text { Time of abdominal pain relief } \\
\text { (based on follow up time) }\end{array}$ & 6 years & 4 years & 1 year & 3 months \\
\hline
\end{tabular}

AP: Abdominal pain; N: Nausea; V: Vomiting; Wt Loss: Weight loss; GES: Gastric emptying study; PSV: Peak systolic velocity; DU: Doppler ultrasound.

\section{Discussion}

In these four cases, the surgical intervention led to the resolution of chronic abdominal pain. All our patients were females, mostly in the 20-40 years age group, and had characteristic chronic abdominal pain exacerbated by eating [1]. 


\subsection{Clinical Manifestation}

Most patients report epigastric and right upper quadrant abdominal pain, aggravated after meals. The fear of provoking pain and delayed gastric emptying can result in weight loss. The abdominal pain can lead to intermittent use of narcotics for pain control plus emergency room visits. In our study, all patients presented with abdominal pain, and 75\% had nausea/vomiting. Only 50\% of the patients had significant weight loss. Weight loss is typically considered as a classic "red flag" in the Rome criteria for suspecting an organic cause [10]. Hence, it is essential to consider organic causes, where weight loss often, but not invariably, occurs in addition to post-prandial abdominal pain [10]. Previous studies have reported abdominal bruit in the upper abdomen in up to $35 \%$ of patients [3]. However, we did not identify this finding in our series.

\subsection{Delayed Gastric Emptying}

Nausea and vomiting can be prominent to the degree that gastric emptying studies indicate a diagnosis of "idiopathic gastroparesis". In our third patient, the gastric emptying study was abnormal at presentation with $31 \%$ meal retention at $4 \mathrm{~h}$, normal being less than $10 \%$ retention by scintigraphic solid meal methodology. Gastric emptying normalized after the surgical intervention. The gastroparesis component is attributed to the abnormal gastric electrical rhythm (e.g., tachygastria) from celiac ganglion compression [9]. These findings have suggested the role of neurogenic pathogenesis resulting from the inhibition of the gastric neuromuscular function [9].

\subsection{Diagnostic Studies}

Most of the patients diagnosed with MALS have previously undergone extensive workups, including abdominal computed tomography (CT) scans, abdominal magnetic resonance imaging (MRI), aortic angiography, and some even undergo surgical procedures including cholecystectomies, appendectomies, or laparoscopic or gynecological procedures in an attempt to make the diagnosis or at least try to relieve the symptoms [11]. These studies are usually repeated, and the average length of time prior to making a diagnosis can be a number of years. In our study, the median length of time that the patients were symptomatic before the diagnosis was 3 (Interquartile range 2-4.8) years.

MALS is a diagnosis that should be considered in patients with chronic post-prandial abdominal pain in the absence of any objective findings, as well as lack of response to all standard empiric therapies for acid-related conditions, irritable bowel syndrome, and gastroparesis. The imaging modalities that are utilized to diagnose MALS include duplex ultrasound, CT angiography, magnetic resonance angiography, and conventional angiography. The clinicians should be aware that these patients may be wrongly diagnosed with functional dyspepsia or irritable bowel syndrome because of the negative workup from a "standard" testing. This could lead to delayed diagnosis due to a clinical belief that the patient has dyspepsia.

The major findings specific for the diagnosis are compression of the celiac artery with respiratory variations, post-compression dilation, and elevated velocities of blood flow $[3,12]$. The compressive effect of the MAL on the celiac artery is relieved during inspiration since the aorta moves anteriorly and inferiorly. Downward diaphragm movement during inspiration relaxes the crura and the compression on the celiac artery. The gold standard for diagnosing MALS is lateral view aortic angiography, which shows more than $50 \%$ narrowing in the origin of the celiac artery, with or without distal dilation, with improvement during inspiration (Figure 2). These findings were well demonstrated in the second patient, in whom the duplex ultrasound showed a PSV of $213 \mathrm{~cm} / \mathrm{s}$ on inspiration and $323 \mathrm{~cm} / \mathrm{s}$ on expiration. Furthermore, the abdominal aortogram was diagnostic for MALS with $>60 \%$ narrowing of the celiac artery on expiration (Figure 2). 


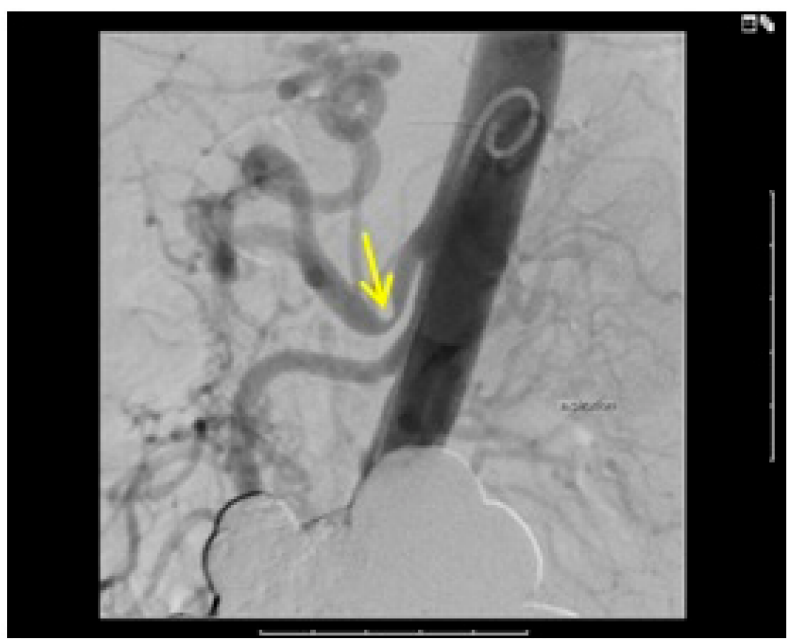

(A)

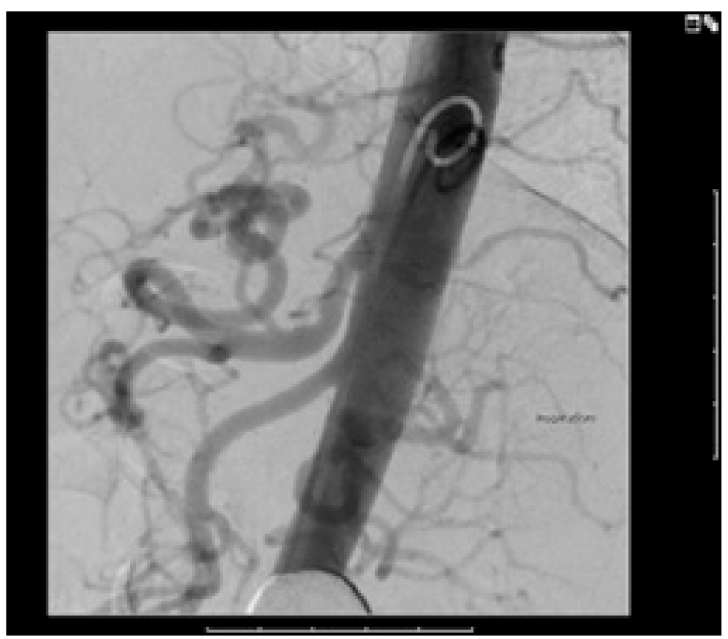

(B)

Figure 2. Lateral views of abdominal aortogram demonstrating the respiratory variations in celiac artery compression at its origin by the median arcuate ligament. (A) Expiratory Phase with more than $60 \%$ compression (yellow arrow) and characteristic distal dilation of celiac trunk just past the narrowed segment. (B) Inspiratory Phase with less than $30 \%$ compression. (Reproduced from McCallum et al. [4] with permission from Practical Gastro).

\subsection{Management}

Surgery is the definitive treatment to divide the median arcuate ligament to decompress the celiac artery and celiac plexus $[3,13]$. Laparoscopic and robotic-assisted laparoscopic approaches have been successfully utilized [14-16]. Intraoperative pre- and post-decompression flow velocity studies are performed routinely to assess success of the procedure. Post-operative angiography may be normal or could show some continuing minimal compression of the celiac artery $(<30 \%)$ during expiration due to the chronicity of the condition inducing some arterial "stiffness" from intimal hyperplasia. The first patient who underwent surgical release of the median arcuate ligament (MAL) demonstrated PSV on expiration reduced from $362 \mathrm{~cm} / \mathrm{s}$ before surgery to $130 \mathrm{~cm} / \mathrm{s}$ after surgery. The patient had a post-operative abdominal aortogram that was normal, and over a 6-year follow-up, she had $100 \%$ relief of abdominal pain, with no more narcotic requirement, stable weight, and improved quality of life.

Endoscopic ultrasound (EUS)-guided celiac block is used to predict response to surgical decompression. The EUS allows injecting the celiac ganglion with xylocaine and monitor for symptom improvement (Figure 3). Improvement of symptoms increases confidence in the diagnosis and hence the decision for surgery. In our study, the fourth patient underwent EUS-guided celiac plexus block, which resulted in amelioration of the pain for 3 to 4 weeks. Another role for EUS-guided celiac block is to enhance the results of post-surgical decompression further in patients who have some residual abdominal pain or some recurrence during long-term follow-up. 


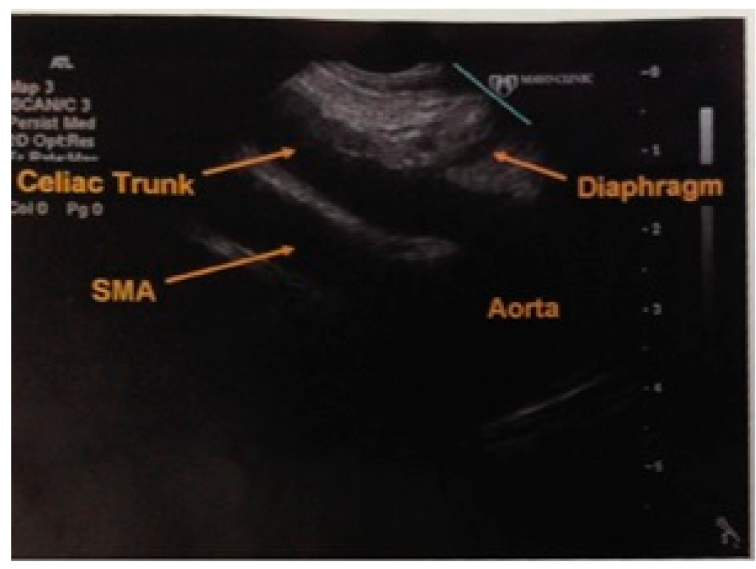

(A)

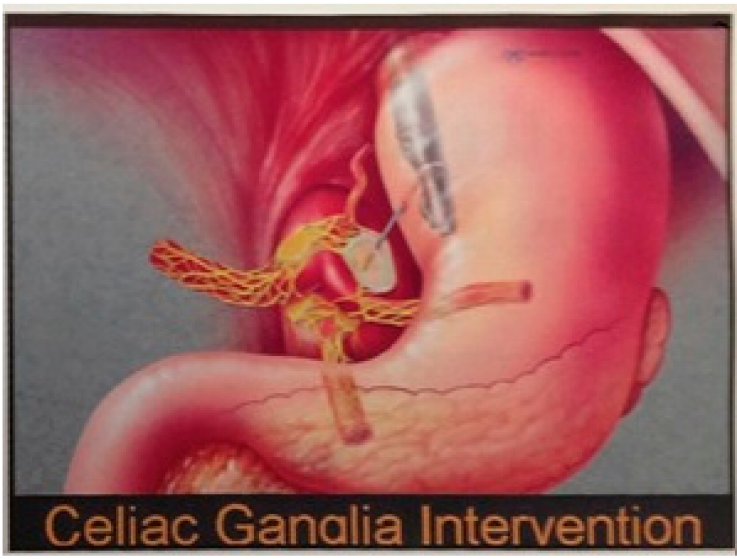

(B)

Figure 3. Endoscopic ultrasound (EUS)-guided celiac plexus neurolysis. (A) EUS showing the anatomic relationship between the diaphragm, aorta, celiac trunk, and the superior mesenteric artery. (B) Demonstration of EUS guided injection of the celiac ganglion. (Reproduced from McCallum et al. [4] with permission from Practical Gastro).

Debate in the radiology literature occurs regarding the roles of celiac artery angioplasty and even vascular reconstruction. These vascular approaches do not address the role of the celiac plexus [17]. Blood flow to the stomach can occur through extensive collateral networks and multiple branches from the superior mesenteric and inferior mesenteric arteries that supplement the contribution of the celiac artery. Therefore, the therapeutic focus should be on the decompression of celiac ganglion.

\section{Conclusions}

MALS is a rare disorder that is often misdiagnosed and not considered in the differential diagnosis, resulting in the exhaustive negative workup, after which suspicion may arise for this entity. Diagnosis relies on the utilization of imaging modalities like angiogram and color Doppler ultrasound with the respiratory variation of celiac blood flow. In addition, there must be a realization that the symptoms are not explained by ischemia. The surgical approach of minimally invasive laparoscopic and robotic techniques focuses on ligating the ligament, and often times results in partial surgical disruption of the celiac plexus, thus overcoming the compression of the celiac ganglion from which the symptoms are emanating. Finally, it is important for the long-term follow-up of these patients to make sure that they are symptom-free, thus confirming the sustainability of the surgery and the accuracy of the diagnosis.

\section{Materials and Methods}

We performed an observational retrospective study with chart review identifying four patients who were referred to the academic GI motility center directed by one of the authors (Dr. Richard McCallum), who saw these patients and provided ongoing care. All the patients presented with chronic abdominal pain with unknown etiology and were later diagnosed with MALS. All these patients already underwent extensive evaluation of their symptoms with no definitive diagnosis and persistence of symptoms. They were comprehensively evaluated to exclude other explanations, and the diagnosis of MALS was confirmed initially with Doppler ultrasound, and definitively with abdominal aortogram. Most of the patients were treated with celiac plexus block and eventually referred to surgical evaluation. All the patients underwent surgical release of the median arcuate ligament (MAL) with an improvement of symptoms, along with improvement in Doppler ultrasound PSV and abdominal aortograms. Baseline clinical characteristics, diagnostic studies, management, and outcomes were reviewed and recorded. 
Author Contributions: Conceptualization, I.A.B., B.R.D., J.R.D., M.G., and R.W.M.; methodology, M.G.; resources, I.A.B., M.G.; data curation, I.A.B., B.R.D., J.R.D.; writing—original draft preparation, I.A.B.; writing-review and editing, I.A.B., M.G., B.R.D., J.R.D. and R.W.M.; supervision, R.W.M. All authors have read and agreed to the published version of the manuscript.

Funding: This research received no external funding.

Institutional Review Board Statement: Ethical review and approval were waived for this study by the Texas Tech University Health Sciences Center El Paso Institutional Review Board (IRB), since this is a case series.

Informed Consent Statement: Informed consent was obtained from all subjects involved in the study.

Data Availability Statement: The data that support the findings of this study are available from the corresponding author upon reasonable request.

Conflicts of Interest: The authors declare no conflict of interest.

\section{References}

1. Dunbar, J.D.; Molnar, W.; Beman, F.F.; Marable, S.A. Compression of the celiac trunk and abdominal angina: Preliminary report of 15 cases. Am. J. Roentgenol. 1965, 95, 731-744. [CrossRef] [PubMed]

2. Rathmell, J.P.; Gallant, J.M.; Brown, D.L. Computed tomography and the anatomy of celiac plexus block. Reg. Anesth. Pain Med. 2000, 25, 411-416. [CrossRef] [PubMed]

3. Jimenez, J.C.; Harlander-Locke, M.; Dutson, E.P. Open and laparoscopic treatment of median arcuate ligament syndrome. J. Vasc. Surg. 2012, 56, 869-873. [CrossRef] [PubMed]

4. McCallum, R.W.; Al-Bayati, I. Median Arcuate Ligament Syndrome. Pract. Gastroenterol. 2015, 21. [CrossRef]

5. Bech, F.; Loesberg, A.; Rosenblum, J.; Glagov, S.; Gewertz, B.L. Median arcuate ligament compression syndrome in monozygotic twins. J. Vasc. Surg. 1994, 19, 934-938. [CrossRef]

6. Okten, R.S.; Kucukay, F.; Tola, M.; Bostanci, B.; Cumhur, T. Is celiac artery compression syndrome genetically inherited?: A case series from a family and review of the literature. Eur. J. Radiol. 2012, 81, 1089-1093. [CrossRef] [PubMed]

7. Schreiber, J.P.; Angle, J.F.; Matsumoto, A.H.; Young, J.S.; Hagspiel, K.D.; Spinosa, D.J. Acute visceral ischemia occurring subsequent to blunt abdominal trauma: Potential culpability of median arcuate ligament compression. J. Trauma Acute Care Surg. 1998, 45, 404-406. [CrossRef] [PubMed]

8. Kim, E.N.; Lamb, K.; Relles, D.; Moudgill, N.; DiMuzio, P.J.; Eisenberg, J.A. Median Arcuate Ligament Syndrome-Review of This Rare Disease. JAMA Surg. 2016, 151, 471-477. [CrossRef] [PubMed]

9. Balaban, D.H.; Chen, J.; Lin, Z.; Tribble, C.G.; McCallum, R.W. Median arcuate ligament syndrome: A possible cause of idiopathic gastroparesis. Am. J. Gastroenterol. 1997, 92, 519-523. [PubMed]

10. Tack, J.; Talley, N.J.; Camilleri, M.; Holtmann, G.; Hu, P.; Malagelada, J.-R.; Stanghellini, V. Functional Gastroduodenal Disorders. Gastroenterology 2006, 130, 1466-1479. [CrossRef] [PubMed]

11. Watson, W.; Sadikali, F. Celiac axis compression: Experience with 20 patients and a critical appraisal of the syndrome. Ann. Intern. Med. 1977, 86, 278-284. [CrossRef] [PubMed]

12. Aschenbach, R.; Basche, S.; Vogl, T.J. Compression of the celiac trunk caused by median arcuate ligament in children and adolescent subjects: Evaluation with contrast-enhanced MR angiography and comparison with Doppler US evaluation. J. Vasc. Interv. Radiol. 2011, 22, 556-561. [CrossRef] [PubMed]

13. Delis, K.T.; Gloviczki, P.; Altuwaijri, M.; McKusick, M.A. Median arcuate ligament syndrome: Open celiac artery reconstruction and ligament division after endovascular failure. J. Vasc. Surg. 2007, 46, 799-802. [CrossRef] [PubMed]

14. Carbonell, A.; Kercher, K.; Heniford, B.; Matthews, B. Laparoscopic management of median arcuate ligament syndrome. Surg. Endosc. 2005, 19, 729. [CrossRef] [PubMed]

15. Jaik, N.P.; Stawicki, S.P.; Weger, N.S.; Lukaszczyk, J.J. Celiac artery compression syndrome: Successful utilization of roboticassisted laparoscopic approach. J. Gastrointest. Liver Dis. 2007, 16, 93.

16. Roddy, S.P. Laparoscopic versus open celiac ganglionectomy in patients with median arcuate ligament syndrome. J. Vasc. Surg. 2010, 52, 1419. [CrossRef]

17. Kohn, G.P.; Bitar, R.S.; Farber, M.A.; Marston, W.A.; Overby, D.W.; Farrell, T.M. Treatment options and outcomes for celiac artery compression syndrome. Surg. Innov. 2011, 18, 338-343. [CrossRef] [PubMed] 